\title{
CD4 T-Lymphocytes Count in HIV-Toxoplasma gondii Co-Infected Pregnant Women Undergoing a Prevention of Mother-to-Child Transmission Program
}

\author{
Gnatoulma Katawa', Malewe Kolou2², Liza Koboyo Nadjir², Essoham Ataba', \\ Gatigbene Bomboma ${ }^{1}$, Simplice Damintoti Karou ${ }^{1}$ \\ ${ }^{1}$ Ecole Superieure des Techniques Biologiques et Alimentaires (ESTBA-UL), Universite de Lome, Lomé, Togo \\ ${ }^{2}$ Laboratoire de Biologie Moleculaire et d’Immunologie (BIOLIM), Universite de Lome, Lomé, Togo \\ Email: *koloumalewe@hotmail.fr
}

How to cite this paper: Katawa, G., Kolou, M., Nadjir, L.K., Ataba, E., Bomboma, G. and Karou, S.D. (2018) CD4 T-Lymphocytes Count in HIV-Toxoplasma gondii Co-Infected Pregnant Women Undergoing a Prevention of Mother-to-Child Transmission Program. Journal of Biosciences and Medicines, 6, 76-84.

https://doi.org/10.4236/jbm.2018.64006

Received: February 25, 2018

Accepted: April 24, 2018

Published: April 27, 2018

Copyright $\odot 2018$ by authors and Scientific Research Publishing Inc. This work is licensed under the Creative Commons Attribution International License (CC BY 4.0).

http://creativecommons.org/licenses/by/4.0/

\section{cc) (i) Open Access}

\begin{abstract}
Toxoplasma gondii ( $T$. gondii) is a parasite responsible of toxoplasmosis, a disease often asymptomatic but with serious consequences in pregnant women and immunocompromised subjects. Objective: This study aimed to investigate the impact of $T$. gondii infection on CD4+ T lymphocytes count in HIV-infected pregnant women. Methods: This was a cross-sectional study of pregnant women co-infected by HIV and $T$. gondii. The study was conducted from January to July 2016 at the Prevention of Mother-to-Child Transmission of HIV (PMTCT) sites in the Health District of Lacs in Togo. Diagnosis of HIV was performed by immuno-chromatographic methods with Determine TM HIV-1/2 and immuno-filtration with Tri-Dot HIV-1 and 2 kits. Presence of anti-toxoplasmic IgG and IgM antibodies was established via enzyme immunoassay using ELISA-BIOREX ${ }^{\bowtie}$ kit. Flow cytometry was used to count CD4+ T lymphocytes. Results: Our study found that of the 4599 pregnant women, 111 (2.41\%) were HIV-positive. Among them, 109 (98.20\%) were infected by HIV-1 and $2(1.98 \%)$ by HIV-2. Antibodies against $T$. gondii were detected in 5.36\% (IgM), 25\% (IgG) and 3.57\% (both IgM and IgG) of HIV 56 infected women. There was no significant difference between CD4 cell count in HIV $(+) / T$. gondii $\operatorname{IgM}(-) / \operatorname{IgG}(-)$ infected pregnant women $(378.8 \pm$ 222.8 cell $/ / \mu \mathrm{l})$ compared to HIV $(+) / T$. gondii/IgM $(+)(457.3 \pm 183.3 \mathrm{cell} / / \mu \mathrm{l})$, HIV $(+) / T$. gondii IgG $(+)(419.4 \pm 287.3 \mathrm{cell} / / \mu \mathrm{l})$ and $\mathrm{HIV}(+) / T$. gondii $\operatorname{IgM} / \operatorname{IgG}(+)(480.5 \pm 252.4 \mathrm{cell} / \mu \mathrm{l})$. Conclusion: This study showed that intracellular parasite $T$. gondii did not alter $\mathrm{CD} 4+\mathrm{T}$ lymphocytes count in $\mathrm{HIV} / \mathrm{T}$. gondii co-infected pregnant women.
\end{abstract}




\section{Keywords}

HIV, Toxoplasma gondii, Co-Infection, CD4+ T Lymphocytes Count

\section{Introduction}

Human immunodeficiency virus (HIV) infection is a global health problem and affects all countries in the world [1]. Globally, about 2.3 million adolescents and young women are living with HIV in 2015 , representing $60 \%$ of the total population of young people (aged 15 - 24 years) living with HIV [2]. However, HIV infection among women varies considerably across regions, with the highest prevalence occurring in sub-Saharan Africa. In this region, 56\% of new HIV infections occurred in women, and this was even higher among young women aged $15-24$ years, accounting for $66 \%$ of new infections [2]. In Togo, the prevalence of $\mathrm{HIV}$ is $2.5 \%$ in the sexually active population aged 15 - 49 years [2]. However, this prevalence is higher in women (3.1\%) than in men (1.7\%).

On the one hand, mother-to-child transmission of HIV is responsible for the majority of HIV infections in children under 15 years of age. Two million children are living with HIV, and of every 10 infected children under 15 years of age, 9 live in sub-Saharan Africa [1]. Mother-to-child transmission of HIV can occur during pregnancy (in utero), childbirth, or breastfeeding. This risk of transmission depends on a number of factors including amniotic fluid infections, vaginal and mammary infections [3], immuno-viral factors such as maternal viral load and CD4+ T lymphocyte rate at delivery [4].

As a result, since 1981 to date, more than 20 million people have died of AIDS leaving behind widows and orphans [1]. The onset of HIV/AIDS has seen an upsurge in opportunistic infections. Most AIDS-related deaths are linked to opportunistic infections that may be parasitic, bacterial, fungal and viral; due to the immune depression caused by HIV in AIDS patients. Toxoplasmosis is one of the opportunistic parasitic infections commonly found among AIDS patients. It is classically benign in the immunocompetent but formidable subject in the immunocompromised subject by its cerebral complications and especially in the pregnant woman by its serious fetal complications [5].

Previous studies on the continent have established that the prevalence of $T$. gondii antibodies among pregnant women varies greatly from country to country. It is $60 \%$ among women of childbearing age in Côte d'Ivoire [6], 54\% among people living with HIV in Uganda [7]; 28.5\% among HIV-infected pregnant women versus $20.20 \%$ among non-infected women in Burkina Faso [8]; $75.4 \%$ in Nigerian pregnant women with occurrence of stillbirths and congenital malformations [9]; 58.4\% in Tunisia [10]; 34.1\% from pregnant women in Sudan [11]; $40.2 \%$ in Senegal, at Dakar [12]; and 53.6\% in Benin [13]. In Togo, it is however not clear the prevalence of toxoplasmosis and HIV co-infections due to the limited number of studies in the previous years. The present study was carried out 
in order to investigate the prevalence of HIV/ Toxoplasma gondii co-infection in pregnant women and to evaluate their immuno-hematological profile.

\section{Material and Methods}

It was a cross-sectional study, which took place from January to July 2016 in the Health District of the Lacs, south-eastern part of Togo.

In total, 4599 pregnant women were enrolled in the study at the first trimester of the pregnancy. Antibodies against T. gondii screening and CD4 T lymphocytes count were performed in $56 \mathrm{HIV}$-infected pregnant women following a PMTCT program. HIV serological screening was performed according to the algorithm for the detection of HIV infection in Togo. Alere Determine TM HIV 1/2 (Alere Medical, Chiba, Japan) was used as a presumptive test and Tri-Dot HIV 1 and 2 (Okhla Industrial Area, New Delhi, India) were used as a differential test when the first was positive. ImmunoComb II HIV1 and 2 Bispot (ImmunoComb II HIV-1 \& 2 Bispot, Orgenics, Yavne, Israel) were used as a confirmatory assay.

The enzyme immunoassay method was used for the detection of Immunoglobulin M (IgM) and Immunoglobulin G (IgG) with the Biorex Diagnostics Limited kit (Antrim Technology Park, United Kingdom).

Flow cytometry using the Cyflow Partec II machine was used for the counting of CD4+ T lymphocytes with the SYSMEX CD4\% easy count kit (Sysmex Partec GmbH, Görlitz, Germany).

Statistical analysis: The data were analyzed on the PRISM 5 software (GraphPad Software, Inc., La Jolla, USA) and Excel 2010. For statistical comparisons, the Kruskal-Wallis test was used and tests were considered statistically significant when $p<0.05$.

\section{Results}

\subsection{Prevalence of HIV among the Pregnant Women}

The prevalence of HIV among the pregnant women was $2.41 \%$ (111/4599). Of these HIV positive individuals, 98.20\% (109/111) were HIV-1 infection and $1.98 \%(2 / 111)$ were HIV-2.

\subsection{Population Characteristics}

Among the $111 \mathrm{HIV}$ positive women, 56 undergoing a PMTCT program were tested for $T$. gondii antibodies and included in this study. The socio-demographic data of 56 pregnant women who have been tested for T. gondii antibodies are presented in Table 1. The participants were aged from 20 to 43 years with an average of $32.29 \pm 5.27$ years. Majority of the women $(62.50 \%)$ were between 30 and 39 years old. Of these, housewives (33.93\%) and shopkeepers $(48.21 \%)$ were the most represented. $71.43 \%$ had formal education while $48.21 \%$ had no formal education and thus were primarily traders (Table 1 ). 
Table 1. Socio-demographic characteristics of the 56 pregnant HIV-infected women tested for $T$. gondii infection.

\begin{tabular}{ccc}
\hline & Number & Percentage \\
\hline Age Range (years) & 16 & 28.57 \\
{$[20-29]$} & 35 & 62.50 \\
{$[30-39]$} & 5 & 8.93 \\
{$[40-43]$} & 56 & 100 \\
Total & & \\
Education & 40 & 71.43 \\
Formal & 16 & 28.57 \\
Non-formal & 56 & 100 \\
Total & & \\
Occupations & 19 & 33.93 \\
Households & 27 & 48.21 \\
Traders & 8 & 14.29 \\
Dressmakers & 2 & 3.57 \\
Planters & 56 & 100 \\
Total & &
\end{tabular}

\subsection{Prevalence of Toxoplasmosis among HIV-Infected Women}

In order to investigate the prevalence of Toxoplasmosis among HIV-infected pregnant women, anti-toxoplasma IgG and IgM antibodies were tested on HIV-infected women $(\mathrm{n}=56)$. We found that $33.93 \%(19 / 56)$ of HIV-infected individuals were positive for $T$. gondii. The prevalence of IgM anti-toxoplasma antibody was $5.36 \%(3 / 56), 25 \%$ (14/56) for IgG anti-toxoplasma while 3.57\% (2/56) were positive for both IgM and IgG (Figure 1).

\subsection{Toxoplasma gondii Infection Did Not Influenced CD4+ T Lymphocytes in HIV Infected Women}

To investigate the effect of Toxoplasma gondii infection on CD4+ T lymphocytes count in HIV-infected women ( $\mathrm{n}=56$ ), CD4+ T lymphocytes counts were performed. Table 2 shows that there is no significant difference between HIV $(+) / T$. gondii $\operatorname{IgM}(-) / \operatorname{IgG}(-), \mathrm{HIV}(+) / T$. gondii $\operatorname{IgM}(+) / \operatorname{IgG}(-), \mathrm{HIV}(+) / T$. gondii $\operatorname{IgM}(-) / \operatorname{IgG}(+)$ and $\mathrm{HIV}(+) / T$. gondii $\operatorname{IgM}(+) / \operatorname{IgG}(+)(p=0.39)$.

\subsection{Toxoplasma gondii Co-Infection Is Not Associated with Stillbirth}

There were no cases of stillbirth in $T$. gondii/HIV co-infected women. In contrast, 7.14\% (4/56) new born from T. gondii (-)/HIV (+) died (Table 3).

\section{Discussion}

The study population consisted of 4599 pregnant women under 24 weeks of 
Table 2. Rate of CD4+ T lymphocytes in women infected with $T$. gondii.

\begin{tabular}{cccc}
\hline & Number & $\begin{array}{c}\text { CD4+ count } \\
(\text { mean } \pm \text { SD })^{\mathrm{a}}\end{array}$ & $p^{\text {-value }}$ val $^{\mathrm{b}}$ \\
\hline $\mathrm{HIV}(+) / T$. gondii $\operatorname{IgM}(-) / \operatorname{IgG}(-)$ & 37 & $378.8 \pm 222.8$ & \\
$\mathrm{HIV}(+) / T$. gondii $\operatorname{IgM}(+) / \operatorname{IgG}(-)$ & 3 & $457.3 \pm 183.3$ & 0.39 \\
$\mathrm{HIV}(+) / T$. gondii $\operatorname{IgM}(-) / \operatorname{IgG}(+)$ & 14 & $419.4 \pm 287.3$ & \\
$\mathrm{HIV}(+) / T$. gondii $\operatorname{IgM}(+) / \operatorname{IgG}(+)$ & 2 & $480.5 \pm 252.4$ & \\
Total & 56 & $382.2 \pm 218.2$ & \\
\hline
\end{tabular}

a. Minimum $=25$; maximum $=1160$; SD: standard deviation. Women were included regardless of their $\mathrm{CD} 4+\mathrm{T}$ cell count. This is why a large difference is observed between the minimum and the maximum, explaining the high value of the standard deviation. b. Comparison of the four means of CD4+ count in the third column using 1 way ANOVA (Kruskal-Wallis test).

Table 3. Stillbirth in T. gondii/HIV co-infection.

\begin{tabular}{lc}
\hline & Stillbirths \\
\hline $\mathrm{HIV}(+) / T$. gondii $\operatorname{IgM}(-) / \operatorname{IgG}(-)$ & 4 \\
$\mathrm{HIV}(+) / T$. gondii $\operatorname{IgM}(+) / \operatorname{IgG}(-)$ & 0 \\
$\mathrm{HIV}(+) / T$. gondii $\operatorname{IgM}(-) / \operatorname{IgG}(+)$ & 0 \\
$\mathrm{HIV}(+) / T$. gondii $\operatorname{IgM}(+) / \operatorname{IgG}(+)$ & 0 \\
\hline
\end{tabular}

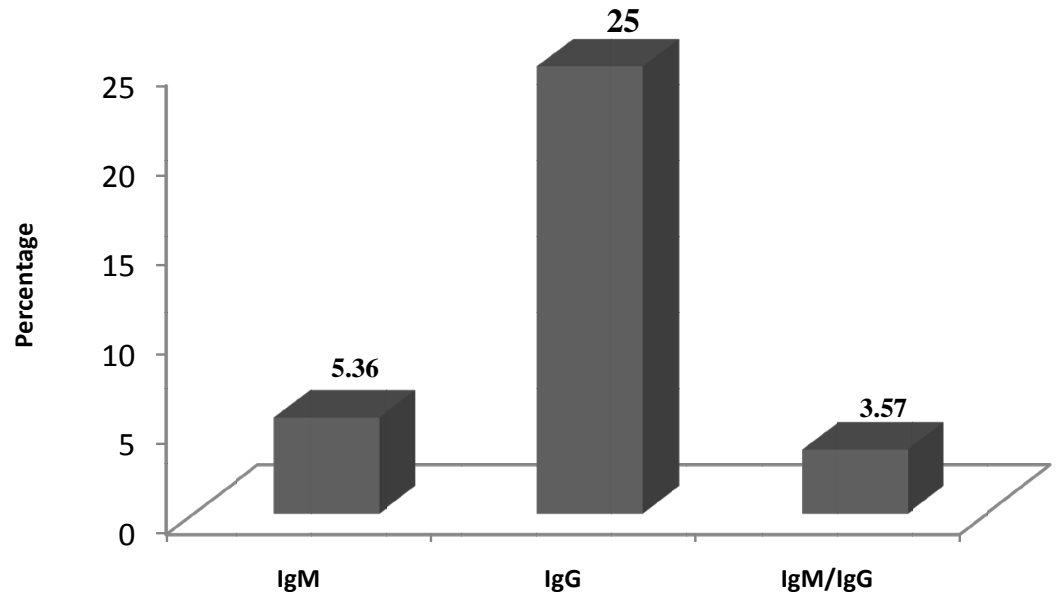

Figure 1. Prevalence of anti-toxoplasma antibodies in HIV positive women.

amenorrhea, who had consented to participate in the PMTCT program in the Lacs Health District. The prevalence of HIV in our population was $2.41 \%$. However, our results ( $2.41 \%$ HIV prevalence) were close to that of the national prevalence of people living with HIV (2.4\%) in Togo in 2015 [2]. The prevalence of $2.41 \%$ in our study is justified by the fact that HIV prevalence in the Maritime region $(3 \%)$ is higher than the national prevalence $(2.4 \%)$ as previously reported [2].

The prevalence of HIV types among the pregnant women in our study was 98.20\% for HIV-1 and 1.98\% for HIV-2. These are however relatively high compared with reports from Burkina Faso [14], a neighboring country in the 
sub-Saharan Region. In Burkina Faso, the gender and age-specific HIV prevalence are reported as $7.3 \%$ among HIV-positive women, with $97.4 \%$ of them living with HIV-1 while $1.8 \%$ of had HIV -2 .

Of the $111 \mathrm{HIV}$-positive women in the present study, 56 women were tested for $T$. gondii infection. Their age ranged from 20 to 43 years, with an average age of $32.29 \pm 5.27$ years. However, the $30-39$ age group were the most represented (62.5\%) followed by the 20 - 29 year-olds $(28.57 \%)$. Therefore, the sexually active population was included in these age groups, which explains this strong representation.

Sixteen $(28.86 \%)$ pregnant women $(n=56)$ in our studied population had no formal education and $48.21 \%(27 / 56)$ were traders. This finding is in agreement with studies which show that less educated women and women living in poverty were more likely to be infected with HIV [15]. The high rate of traders is explained by the fact that the Lacs District shares borders with Benin and that of Abidjan-Lagos, therefore serves as strategic commercial city.

Positive toxoplasmic serology with only the presence of IgM antibodies indicates a recent infection with toxoplasma [16]. This means that $5.36 \%$ of the women in our study who were positive for IgM suffer from a recent infection. Positive toxoplasmic serology with only the presence of IgG antibodies usually reflects an old infection by toxoplasma. This means that $25 \%$ of pregnant women that presented with positive IgG in our study suffer from an old infection, so probably contracted $T$. gondii infection before pregnancy. Toxoplasmic serology positive to both IgM and IgG is indicative of ongoing sero-conversion [17]. Thus, $3.57 \%$ of women in this study were in the sero-conversion phase. Our results are similar to sero-prevalence data of some African countries: For instance $27.00 \%$ to IgG in Uganda [18], 25\% to IgG in Dakar (Senegal) according to Faye [12], $21 \%$ to IgG in blood donors in Mali [19]; 4.70\% to IgM and $27.20 \%$ to IgG in Burkina Faso [14]. In Togo, few studies were carried out on cases of co-infections of toxoplasmosis and HIV, but Apetse found a prevalence of 54\% in patients living with HIV (PLHIV) hospitalized at the neurological unit of Sylvanus Olympio Teaching Hospital of Lome, Togo [20].

The similarity of the results in other countries may be accounted for by the fact that the tropical region is favorable to the survival of oocysts in the soil but also by the consumption of contaminated food and to a lesser extent by the coat of animals (cats) [21]. Almost 75\% of pregnant women in our study were negative for anti-IgG serology, therefore in the absence of adequate prevention strategies, these women would be at risk of contracting toxoplasma during pregnancy.

Concerning CD4+ T lymphocytes, the mean rate of $382.2 \pm 218.2$ cells/ $\mu \mathrm{lob}$ served in our study is higher than 143 cells/ $\mu$ l, found by Dokekias in Brazzaville (Congo) [22]. It is known that HIV causes a slow and progressive deterioration of the host's immune system, which makes an individual prone to several opportunistic infections [23]. In our population, 9 (16.07\%) of the 56 women had a CD4+ T lymphocytes cell count less than 200 cells/ $\mu$ l. Unlike our results, Djibril 
et al. found $83.6 \%$ cases of CD4+ T lymphocytes cell count less than 200 cells/ $\mu \mathrm{l}$ in patients living with HIV (PLHIV) who were hospitalized at the Sylvanus Olympio Teaching Hospital of Lome, Togo [24]. This difference is due to that it is a severe immunodepression that usually motivates hospitalization in these patients.

The prevalence of anti- Toxoplasma gondii antibodies in HIV infected women was $5.36 \%$ for $\operatorname{IgM}(3 / 56)$, 25\% for $\operatorname{IgG}(14 / 56)$ and $3.57 \%$ for both IgM and IgG (2/56). Patients who had recent infection with $T$. gondii $(\operatorname{IgM}+)$ had a higher CD4+ T cell count but the difference was not statistically significant $(p=0.39)$. The co-infection of HIV/T. gondii did not influence the CD4+ T lymphocytes count in our study. This could be due to the PMTCT program. This program would also explain the fact that no stillbirths have been reported in women co-infected with HIV and T. gondii. The follow-up of HIV-infected women during the PMTCT program is an asset that allows at the same time the detection and treatment of active toxoplasmosis. This therefore limits the risk of transmission of the disease to the fetus.

\section{Conclusion}

Toxoplasmosis is a threat to pregnant women and the immunocompromised because of the risk of complications. This study reveals a high prevalence of HIV infection in pregnant women $(2.41 \%)$ in the Health District of the Prefecture of Lacs. IgM seroprevalence estimated at $5.36 \%$ and IgG seroprevalence at $25 \%$ show that a large number of pregnant women are exposed to toxoplasma contamination. It is essential that health policies decide on the systematic monitoring of women during pregnancy in order to prevent fetal contamination for better expectations in the fight against vertical transmission of HIV and T. gondii. The study shows also that the PMTCT program could help in the maintaining of a good immunity for the purpose of fighting opportunistic infections.

\section{References}

[1] United Nations Programme on HIV/AIDS (2016) AIDS by the Numbers. Joint United Nations Programme on HIV/AIDS (UNAIDS), Geneva.

[2] United Nations Programme on HIV/AIDS (2015) HIV and AIDS estimates (2015). United Nations Programme on HIV/AIDS (UNAIDS), Geneva.

[3] Casalini, C., Signorini, L., Beltrame, A., Matteelli, A. and Carosi, G. (2001) Vertical Trasmission of Human Immunodeficiency Virus (HIV) and Other Sexually Transmitted Infections (STI). Minerva Ginecologica, 53, 177-192.

[4] Rouzioux, C., Chaix, M.L., Burgard, M. and Mandelbrot, L. (2002) HIV and Pregnancy. Pathologie Biologie, 50, 576-579. https://doi.org/10.1016/S0369-8114(02)00353-X

[5] Stascheit, F., Paul, F., Harms, L. and Rosche, B. (2015) Toxoplasma gondii Seropositivity Is Negatively Associated with Multiple Sclerosis. Journal of Neuroimmunology, 285, 119-124. https://doi.org/10.1016/j.jneuroim.2015.05.011

[6] Adou-Bryn, K.D., Ouhon, J., Nemer, J., Yapo, C.G. and Assoumou, A. (2004) Serological Survey of Acquired Toxoplasmosis in Woman of Childbearing Age in Yo- 
poug on (Abidjan, Cote d'Ivoire). Bulletin de la Societe de pathologie exotique, 97, 345-348.

[7] Lindstrom, I., Kaddu-Mulindwa, D.H., Kironde, F. and Lindh, J. (2006) Prevalence of Latent and Reactivated Toxoplasma gondii Parasites in HIV-Patients from Uganda. Acta Tropica, 100, 218-222. https://doi.org/10.1016/j.actatropica.2006.11.002

[8] Simpore, J., Pietra, V. and Savadogo, A. (2006) Reduction of Mother-to-Child Transmission of HIV at Saint Camille Medical Centre in Burkina Faso. Journal of Medical Virology, 78, 148-152. https://doi.org/10.1002/jmv.20521

[9] Onadeko, M.O., Joynson, D.H., Payne, R.A. and Francis, J. (1996) The Prevalence of Toxoplasma Antibodies in Pregnant Nigerian Women and the Occurrence of Stillbirth and Congenital Malformation. African Journal of Medicine and Medical Sciences, 25, 331-334.

[10] Bouratbine, A.E., Siala, M.K., Chahed, K.A. and Ben-Ismail, R. (2001) Seroepidemiologic Profile of Toxoplasmosis in Northern Tunisia. Parasite, 8, 61-66.

https://doi.org/10.1051/parasite/2001081061

[11] Elnahas, A., Gerais, A.S., Elbashir, M.I., Eldien, E.S. and Adam, I. (2003) Toxoplasmosis in Pregnant Sudanese Women. Saudi Medical Journal, 24, 868-870.

[12] Faye, O., Leye, A., Dieng, Y., Richard-Lenoble, D. and Diallo, S. (1998) Toxoplasmosis in Dakar. Seroepidemiologic Sampling of 353 Women of Reproductive Age. Bulletin de la Societe de pathologie exotique, 91, 249-250.

[13] Rodier, M.H., Berthonneau, J., Bourgoin, A., Giraudeau, G. and Agius, G. (1995) Seroprevalences of Toxoplasma, Malaria, Rubella, Cytomegalovirus, HIV and Treponemal Infections among Pregnant Women in Cotonou, Republic of Benin. Acta Tropica, 59, 271-277. https://doi.org/10.1016/0001-706X(95)00087-U

[14] Ouermi, D., Simpore, J., Belem, A.M., Sanou, D.S., Karou, D.S., Ilboudo, D., et al. (2009) Co-Infection of Toxoplasma gondii with HBV in HIV-Infected and Uninfected Pregnant Women in Burkina Faso. Pakistan Journal of Biological Sciences, 12, 1188-1193. https://doi.org/10.3923/pjbs.2009.1188.1193

[15] Singh, R.K. and Patra, S. (2015) What Factors Are Responsible for Higher Prevalence of HIV Infection among Urban Women than Rural Women in Tanzania? Ethiopian Journal of Health Sciences, 25, 321-328.

https://doi.org/10.4314/ejhs.v25i4.5

[16] Montoya, J.G. (2002) Laboratory Diagnosis of Toxoplasma gondii Infection and Toxoplasmosis. The Journal of Infectious Diseases, 185, S73-S82. https://doi.org/10.1086/338827

[17] Fricker-Hidalgo, H., Cimon, B., Chemla, C., Darde, M.L., Delhaes, L., L'Ollivier, C., et al. (2013) Toxoplasma Seroconversion with Negative or Transient Immunoglobulin M in Pregnant Women: Myth or Reality? A French Multicenter Retrospective Study. Journal of Clinical Microbiology, 51, 2103-2111. https://doi.org/10.1128/JCM.00169-13

[18] Zumla, A., Savva, D., Wheeler, R.B., Hira, S.K. and Luo, N.P. (1991) Toxoplasma Serology in Zambian and Uganda Patients Infected with the Human Immunodeficiency Virus. Transactions of the Royal Society of Tropical Medicine and Hygiene, 85, 227-229. https://doi.org/10.1016/0035-9203(91)90034-V

[19] Maiga, I., Kiemtore, P. and Tounkara, A. (2001) Prevalence of Antitoxoplasma Antibodies in Patients with Acquired Immunodeficiency Syndrome and Blood Donors in Bamako. Bulletin de la Societe de Pathologie Exotique, 94, 268-270.

[20] Apetse, K., Assogba, K., Kevi, K., Balogou, A.A.K., Pitche, P. and Grunitzky, E. 
(2015) Opportunistic Infections of HIV/AIDS in a Neurological Unit in Togo. African Journal of Neurological Sciences, 33, 34-40.

[21] Wilking, H., Thamm, M., Stark, K., Aebischer, T. and Seeber, F. (2016) Prevalence, Incidence Estimations, and Risk Factors of Toxoplasma gondii Infection in Germany: A Representative, Cross-Sectional, Serological Study. Scientific Reports, 6, Article No. 22551. https://doi.org/10.1038/srep22551

[22] Dokekias, A.E., Galiba, F.O. and Bokilo, A.D. (2008) Evaluation of Antiretroviral Therapy in HIV-Infected Adults in the Derpartement of Haematology, University Hospital of Brazaville, Congo. Bulletin de la Societe de pathologie exotique et de ses filiales, 101, 109-112.

[23] Kaplan, J.E., Hu, D.J., Holmes, K.K., Jaffe, H.W., Masur, H. and De Cock, K.M. (1996) Preventing Opportunistic Infections in Human Immunodeficiency Virus-Infected Persons: Implications for the Developing World. The American Journal of Tropical Medicine and Hygiene, 55, 1-11.

https://doi.org/10.4269/ajtmh.1996.55.1.TM0550010001

[24] Djibril, M., Ouedraogo, S., Balaka, A., Tchamdja, T., Djagadou, K. and Agbetra, A. (2015) Profile of People Living with HIV in Intensive Medical Care in Togo; Epidemiological and Evolutionary Aspects. Journal of Hematology and Thromboembolic Diseases, 3, 201. https://doi.org/10.4172/2329-8790.1000201 